\title{
Implementing specific oral tolerance induction to milk into routine clinical practice: experience from first 50 patients
}

This article was published in the following Dove Press journal: Journal of Asthma and Allergy

28 January 2014

Number of times this article has been viewed

\author{
David Luyt \\ Kristian Bravin \\ Jessica Luyt \\ Children's Allergy Service, University \\ Hospitals of Leicester, Leicester, UK
}

Background: Although the natural history of cow's milk allergy is to resolve during childhood or adolescence, a small but significant proportion of children will remain allergic. Specific oral tolerance induction to cow's milk (CM-SOTI) provides a treatment option in these children with continuing allergy with high success rates. However current sentiment limits widespread availability as existing reports advise that it is too soon to translate CM-SOTI into routine clinical practice.

Methods: In January 2007 we implemented a slow up-dosing CM-SOTI program. Eligible subjects were identified at routine visits to our children's allergy clinic. Persisting cow's milk allergy was confirmed from recent contact symptoms or a positive baked milk challenge. As allergic symptoms are common during CM-SOTI, families were provided with ready dietetic access for advice on dosing and symptom treatment. Subjects were continuously monitored at subsequent clinic visits or telephonically, where no longer followed, for a median of 49 months.

Results: The first 50 subjects ( 35 males) treated ranged in age from 5.1 to 15.8 years (median 10.3 years). Full tolerance $(250 \mathrm{~mL})$ was achieved in 23 subjects, 9 without any symptoms, and a further 9 achieved partial tolerance with continued ingestion. Eighteen children failed to achieve any regular milk ingestion; 11 because of persistent or significant symptoms whilst 8 withdrew against medical advice. Allergic symptoms were predominantly mild to moderate in severity, although 2 cases needed treatment with inhaled salbutamol and a further 2 required intramuscular adrenaline. Clinical tolerance, both full and partial, persists beyond 5 years.

Conclusion: We have demonstrated that a CM-SOTI program can be successfully and safely implemented as routine clinical practice with acceptable compliance during prolonged home up-dosing, despite frequent allergic symptoms, and for up to 4 years after starting treatment. CM-SOTI can thus be put into practice more widely where there is appropriate support.

Keywords: cow's milk allergy, specific oral tolerance induction, oral desensitization, compliance, safety

\section{Introduction}

The conventional management of food allergy of dietary avoidance is no longer regarded as the only acceptable treatment option. It leaves affected individuals at constant risk of the physical and psychological consequences of allergic reactions through inadvertent contact. This is particularly pertinent where the culprit allergen is commonly encountered in processed foods and thus difficult to avoid in everyday life, where the allergy is likely to persist or where the allergic reactions are potentially severe. ${ }^{1}$ Also, as food allergy is increasing in prevalence and persisting longer, it poses increasing health and safety challenges to parents and carers. ${ }^{2}$

As the natural history of cow's milk allergy (CMA) is resolution during childhood or adolescence, current management is allergen avoidance followed by gradual
Correspondence: David Luyt Children's Allergy Service, Leicester Royal Infirmary, University Hospitals of Leicester, Leicester, UK, LEI 5WW

Tel +44 II6 2586194

Fax $+44 I I 62587637$

Email david.luyt@uhl-tr.nhs.uk submit your manuscript $\mid$ www.dovepress.com

Dovepress

http://dx.doi.org//0.2/47/JAA.S5328|
Journal of Asthma and Allergy 2014:7 I-9

(c) (i) (5) $\odot 2014$ Luyt et al. This work is published by Dove Medical Press Limited, and licensed under Creative Commons Attribution - Non Commercial (unported, v3.0) BY LC License. The full terms of the License are available at http://creativecommons.org/licenses/by-nc/3.0/. Non-commercial uses of the work are permitted without any further permission how to request permission may be found at: http://www.dovepress.com/permissions.php 
reintroduction until tolerance develops. ${ }^{3}$ There is however, a small but significant proportion of affected individuals in whom the allergy will persist. These are more commonly children with other food allergies, frequently to eggs, who are therefore subject to wider dietary restrictions. ${ }^{4}$ These individuals would thus be ideal candidates for treatment of their CMA.

Specific oral tolerance induction (SOTI) is one such treatment option whereby tolerance is achieved by oral exposure to increasing doses of the specific food allergen. ${ }^{5}$ There are now a number of reports on SOTI to milk (CM-SOTI), although with widely varying up-dosing regimens in both the rate and concentration of dose increases. Nonetheless, all studies demonstrated the same three patterns of response: failure with persistent symptoms to even trace contact, partial tolerance raising the reaction threshold dose, and full tolerance allowing free contact. The frequency of the latter ranged from $62 \%$ to $80 \%$. In addition to these high success rates, CM-SOTI was also shown to be a safe treatment, as sideeffects or allergic symptoms, although commonly reported in all studies, were predominantly mild to moderate in severity, affecting mostly the skin and gastrointestinal system. ${ }^{6-21}$ Despite these favorable reports, most authors feel that it is too early to translate CM-SOTI into clinical practice. ${ }^{22}$

The objectives of any treatment for food allergy should be to attain lasting tolerance, both immunological and psychological, in the affected individual. Unlike immunotherapy where immune tolerance, and hence symptom relief, persists well beyond completion of the treatment program, in SOTI, regular exposure is necessary to maintain immune modulation. ${ }^{23}$ This may be stressful to the child and his or her family as omission of the daily dose of milk can lead to recurrence of symptoms. ${ }^{24}$ However, a study of long-term follow-up of more than 4 years showed continuing dietary compliance with consequent maintenance of tolerance in most patients. ${ }^{25}$

In 2007, in the Children's Allergy Service of the Leicester Royal Infirmary, we introduced a CM-SOTI clinical program using a slow up-dosing home administration protocol. ${ }^{10}$ The objective of the study was to demonstrate the short and long-term effectiveness and safety of CM-SOTI as part of a clinical service. This report presents our experiences with the first 50 patients enrolled.

\section{Methods}

\section{Patient enrollment and inclusion criteria}

We started our CM-SOTI program in January 2007 after obtaining approval from our institution's clinical ethical committee. Children with persistent CMA were identified and recruited from the allergy clinic. Inclusion criteria for recruitment were children over 5-years-old with a history of acute-onset CMA who had experienced symptoms within the past 2 months following accidental $\mathrm{CM}$ exposure, or children who reacted to an open oral baked milk challenge (Figure 1).

A challenge test was performed to confirm persistence of CMA where there were no recent contact symptoms. We chose to use baked milk biscuits as the challenge food as this form of CM is less allergenic than raw milk. ${ }^{26}$ Subjects who failed the challenge were enrolled for CM-SOTI. Where the subject completed the challenge without an allergic reaction, he or she continued with regular baked milk contact at home under dietetic supervision and with the advice to increase contact as tolerated. ${ }^{27}$ If the subject failed to progress past milk biscuits, CM-SOTI was considered at a later stage.

Clinical data recorded included concomitant food allergies and other atopic conditions, initial allergic symptoms and the most severe reactions and the age at which these symptoms occurred, and skin prick test results ${ }^{28}$ from clinic allergy assessments. Allergic symptoms were graded into mild-moderate (involving the skin or gastrointestinal tract) or serious (involving respiratory or cardiovascular systems).

\section{Oral tolerance induction protocol}

When CM-SOTI was initiated, the subject was seen in our hospital medical daycare ward jointly by the clinician and the dietitian. A history was obtained and clinical examination performed to exclude any recent illness that would delay the program. Written informed consent was obtained and antihistamines and an adrenaline autoinjector were prescribed, with instructions and training to treat any allergic reactions. The family was then instructed on the up-dosing protocol and supplied with measuring pipettes for accurate dosing. They were advised that during up-dosing all other forms of dairy

\author{
Baked milk challenge \\ I. Small crumb of biscuit \\ 2. Large crumb of biscuit \\ 3. $1 / 16$ of biscuit \\ 4. I/8 of biscuit \\ 5. I/4 of biscuit \\ 6. Remainder of biscuit
}

Figure I Cow's milk oral open challenge protocol (hospital-based).

Notes: Challenge food is a malted milk biscuit; the biscuit should ideally contain whole milk protein/powder ( $<$ I g per biscuit); 15-30 minute observation periods between doses; 60-minute observation period (minimum) at the end of the challenge. 
had to be avoided, and that if an illness occurred (eg, fever, common cold) appropriate treatment should be given but dose increases were to be postponed.

The subject received the first dose in hospital and was monitored for 1 hour. All subsequent doses were ingested at home. As allergic symptoms are common during up-dosing, we ensured easy telephone access for the families for advice on CM dose adjustment and treatment (Figure 2).

We used the three-stage, 67-day, slow up-dosing protocol described by Staden et al. ${ }^{9}$ In the first stage, a $1 \%$ solution (one drop of milk diluted with 99 drops of water) is used. The subject ingests 1 drop as the first dose. This is equivalent to about $0.02 \mathrm{mg}$ of milk. There are eleven subsequent incremental steps in this stage to a top dose of 20 drops $(0.33 \mathrm{mg})$. In the second stage, a $10 \%$ solution (one drop of milk diluted with ten drops of water) is used, starting at three drops $(0.50 \mathrm{mg})$ and increasing over the subsequent eight steps to 20 drops $(3.3 \mathrm{mg})$. The third stage, which uses pure milk, starts at step 22: equivalent to day 22 if up-dosing is uninterrupted. The rate of up-dosing accelerates as tolerance increases with, for example, a dose of 20 drops $(33 \mathrm{mg}$ ) at step 30, $13 \mathrm{~mL}(429 \mathrm{mg})$ at step 40, $27.5 \mathrm{~mL}(908 \mathrm{mg})$ at step 50, and $150 \mathrm{~mL}(4,950 \mathrm{mg})$ at step 60 . The targeted top dose of milk ingested daily is $250 \mathrm{~mL}(8,250 \mathrm{mg})$.

\section{Patient follow-up and outcome}

Parents were encouraged during up-dosing to contact the dietitian if the subject developed allergic symptoms. Once the subject achieved a stable ingestion dose of CM, as assessed by tolerance without symptoms, regular follow-up was maintained where possible. Subjects were reviewed at least every 6 months either in clinic, usually for concomitant allergic conditions or via telephone by the dietitian where clinic follow-up was no longer required.

Outcomes were classified as full tolerance, partial tolerance, or treatment failure according to the individual's daily milk ingestion at the end of the up-dosing period. Subjects with full tolerance were able to ingest the targeted top dose of $250 \mathrm{~mL}$ of CM daily without symptoms, while those with partial tolerance could continually ingest smaller quantities. Those who failed experienced symptoms that precluded any progression of up-dosing or after achieving some partial tolerance, declined to continue when symptoms developed or for personal reasons.

\section{Statistical analysis}

The statistical analysis was performed using chi-square analysis for categorical comparisons and the Wilcoxon matched-pairs signed-ranks test for continuous variables. Differences were considered significant when $P<0.05$ (Social Science Statistics). ${ }^{29}$

\section{Results}

\section{Patient demographics} and allergic presentations

The 50 subjects ( 35 boys) enrolled in the CM-SOTI program ranged in age at onset from 5.1-15.8 (median 10.3) years. Other atopic conditions were reported in 41 subjects, with asthma in 25 , rhinitis in 26, and eczema in 31 . Concomitant food allergies were present in 35 subjects, with one other food allergy in 17 subjects, two in eleven subjects, and three or more in seven of the subjects. Most common other food allergies were to eggs and nuts. Allergic symptoms reported in the most severe reactions from previous milk ingestion affected the skin (erythema, urticaria, swelling, eczema) or gastrointestinal tract (vomiting, diarrhea, abdominal distension, abdominal pain) only in 31 subjects and the respiratory (wheeze, cough, stridor, difficulty breathing) and cardiovascular (pallor) systems, either alone or in addition, in the remaining 19. Nineteen participants were therefore considered to have experienced serious symptoms, and in eight of these subjects, symptoms had worsened in severity from their initial presentation. Allergic status was assessed at clinical encounter with skin prick tests; 17 participants tested negative, positive tests ranged in wheal size from $3 \mathrm{~mm}$ to $9 \mathrm{~mm}$. Subjects with concomitant asthma or other allergies were more likely to achieve full tolerance (Table 1).

\section{Oral tolerance induction outcomes}

Twenty-three subjects accomplished full tolerance, eleven of whom completed the up-dosing protocol in the target 67 days; that is, without needing to slow up-dosing because of allergic symptoms. Nine participants had no symptoms. One subject experienced tingling of his tongue that passed spontaneously with 20 drops of $10 \%$ (day 21) and again at $3 \mathrm{~mL}$ neat (day 33), and another participant had mild diarrhea with seven drops 1\% (day 7). One subject withdrew because of repeated symptoms of oral swelling on three attempts at four drops of neat. After a 3-month hiatus, the subject restarted treatment and achieved full tolerance in 67 days.

Nine subjects had achieved partial tolerance and agreed to continue with regular ingestion at their individually-determined lower doses. These range from 30 drops of $10 \%$ to $100 \mathrm{~mL}$ of neat, equivalent to $4.2 \mathrm{mg}$ and 3,400 mg, respectively (Table 2). Where subjects were on low doses requiring dilutions, the 
Table I Comparison of full tolerance with partial and failed tolerance groups

\begin{tabular}{|c|c|c|c|}
\hline Variable & $\begin{array}{l}\text { Full } \\
(n=23)\end{array}$ & $\begin{array}{l}\text { Partial/failed } \\
(n=27)\end{array}$ & $P$-value \\
\hline Age (median, range), y & $7.6(5.1-15.8)$ & $7.7(5.6-14.8)$ & \\
\hline Sex $(n, \%)$, males & $18(75)$ & $17(63)$ & NS \\
\hline \multicolumn{4}{|l|}{ Atopic history } \\
\hline Other food allergy, n (\%) & $18(75)$ & $17(74)$ & NS \\
\hline $\mathrm{Hx} / \mathrm{o}$ asthma, n (\%) & $17(63)$ & $8(35)$ & 0.002 \\
\hline Hx/o rhinitis, $\mathrm{n}(\%)$ & $16(60)$ & $10(43)$ & NS \\
\hline Hx/o eczema, n (\%) & $17(63)$ & $14(6 \mathrm{I})$ & NS \\
\hline Hx/o other allergy, n (\%) & $22(95)$ & $17(74)$ & 0.006 \\
\hline \multicolumn{4}{|l|}{ Clinical presentation } \\
\hline \multicolumn{4}{|l|}{ Symptoms with first reaction } \\
\hline Age (median, range), mo & $2(0-36)$ & $4(0-18)$ & \\
\hline Serious symptoms, $\mathrm{n}(\%)$ & $4(17)$ & $7(26)$ & NS \\
\hline \multicolumn{4}{|c|}{ Symptoms with most severe reaction } \\
\hline Age (median, range), mo & $24(0-120)$ & $6(1-84)$ & \\
\hline Serious symptoms, $\mathrm{n}(\%)$ & $8(35)$ & II (4I) & NS \\
\hline $\begin{array}{l}\text { Worsening symptoms, } \\
\mathrm{n}(\%)\end{array}$ & $4(17)$ & $4(15)$ & NS \\
\hline \multicolumn{4}{|l|}{ Most recent exposure } \\
\hline Age (median, range), mo & $76(18-180)$ & $72(14-156)$ & \\
\hline Trace tolerance, no (\%) & $12(52)$ & $15(56)$ & NS \\
\hline \multicolumn{4}{|l|}{ SPT wheal } \\
\hline Size (median, range) $\mathrm{mm}$ & $2.5(0-8)$ & $4(0-7)$ & \\
\hline Negative, no (\%) & $9(45)$ & $8(31)$ & NS \\
\hline
\end{tabular}

Note: Worsening symptoms is the number with serious symptoms after presenting symptoms.

Abbreviations: $\mathrm{Hx} / \mathrm{o}$, history of; mo, months; $\mathrm{n}$, number; NS, not significant; SPT, skin prick test; $y$, years.

dietitian identified a more easily acceptable form of milk for daily ingestion (eg, chocolate buttons).

The remaining 18 subjects failed to achieve any regular milk ingestion. The family was advised to discontinue the program in eleven cases because of persistent or significant symptoms. Seven subjects withdrew against medical advice, even though in one case (MW), the subject demonstrated considerable tolerance (Table 3).

Allergic symptoms were common, affecting 41 (82\%) participants, were predominantly mild to moderate in severity (Table 4), and mostly resolved with dose adjustment and antihistamines. Inhaled salbutamol was necessary to manage respiratory symptoms in two subjects, and two other subjects required intramuscular (IM) adrenaline for anaphylaxis.

The events leading up to anaphylaxis requiring adrenaline were as follows: Subject ST was highly atopic with asthma and eczema and multiple food allergies, including allergy to milk. He achieved tolerance at $30 \mathrm{~mL}$ neat milk daily and had been taking that dose for 3 weeks. The day after missing his daily dose, he took his usual dose and shortly thereafter undertook exercise. Subject RE also had asthma. In the weeks leading up to his reaction his asthma control had deteriorated, but his mother had not realized that this might be associated with milk contact and had not notified the dietitian.

\section{Follow-up}

Continuous contact and consequent follow-up has been maintained with all but two families where the subject achieved full tolerance and in all with partial tolerance. All subjects in the full tolerance group continue to ingest milk and other dairy products freely. The length of followup of those with full tolerance ranged from 4-64 months (median 49 months), with ten for $>48$ months, six for $24-47$ months, and five for $<23$ months; and of those with partial tolerance ranged from 12-57 months (median 49 months), with 5 for $>48$ months, one for $24-47$ months, and three for $<24$ months.

\section{Discussion}

CM-SOTI is now an established treatment for persistent CMA. However, as with any recently introduced therapeutic modality, concerns arise about protocols, efficacy, safety, and long-term effects, and consequently, whether the treatment can be implemented as routine practice outside closely monitored research conditions. Current opinion favors limiting the implementation of CM-SOTI with many protocols advocating up-dosing only in hospital, either as day case or inpatient procedures. ${ }^{9,15,16}$ We present our experience of implementing a slow home up-dosing CM-SOTI program into our routine clinical practice.

In immune modulation, either allergen immunotherapy (AIT) or SOTI, the rates at which treatment doses are increased are arbitrary but are limited by side effects that prevent achievement of the target dose. In hymenoptera subcutaneous immunotherapy, for example, duration of updosing ranges from 3.5 hours to 15 weeks. ${ }^{30,31}$ Similarly, there are rush $^{13,14,19}$ and slow ${ }^{9,12,21}$ up-dosing protocols in CM-SOTI, with pros and cons to both. Rush protocols require hospital visits or admission for up-dosing and carry a greater risk of serious side effects, but supervised up-dosing encourages compliance and provides medical support when the patient is most at risk of an allergic reaction. ${ }^{15}$ Slow protocols are timeconsuming and possibly onerous, with the consequent risk of poor compliance or protocol violations but are less likely to trigger serious allergic reactions. ${ }^{16}$ Available resources, particularly the costs and availability of day case or inpatient hospital beds, could influence the choice of protocol. We have successfully implemented a home up-dosing CM-SOTI program. We chose the protocol because it afforded us the independence to initiate treatment in individual patients 
Table 2 Characteristics of children who achieved partial tolerance

\begin{tabular}{|c|c|c|c|c|c|}
\hline Patient & Age at start & $\begin{array}{l}\text { Length of } \\
\text { treatment }\end{array}$ & $\begin{array}{l}\text { Ongoing CM } \\
\text { dose }\end{array}$ & $\begin{array}{l}\text { Maximum CM } \\
\text { dose }\end{array}$ & $\begin{array}{l}\text { Symptoms evolution during } \\
\text { CM-SOTI (triggering dose) }\end{array}$ \\
\hline EB $(f)$ & $6 \mathrm{y}, 2 \mathrm{mo}$ & 157 days & $20 \mathrm{~mL}$ neat & $30 \mathrm{~mL}$ neat & $\begin{array}{l}\text { Lips blistered (eight drops neat and } \\
2.5 \mathrm{~mL} \text { neat); reached } 30 \mathrm{~mL} \text { neat but } \\
\text { with frequent tongue reactions; settled } \\
\text { at } 20 \mathrm{~mL} \text { neat in any form. }\end{array}$ \\
\hline$A C(f)$ & $8 \mathrm{y}, 2 \mathrm{mo}$ & 120 days & $80 \mathrm{~mL}$ neat & $100 \mathrm{~mL}$ neat & $\begin{array}{l}\text { Throat swelling (three drops neat), } \\
\text { occurred three times before able to } \\
\text { progress; facial flushing at } 100 \mathrm{~mL} \text { neat; } \\
\text { symptoms settled at } 80 \mathrm{~mL} \text { neat. }\end{array}$ \\
\hline LG (f) & $6 \mathrm{y}, 3 \mathrm{mo}$ & 320 days & $6 \mathrm{~mL}$ neat & $6 \mathrm{~mL}$ neat & $\begin{array}{l}\text { Lip blistered (five drops neat and } 2 \mathrm{~mL} \\
\text { neat); changed to chocolate buttons } \\
\text { and increased to equivalent of } 6 \mathrm{~mL} \text {. }\end{array}$ \\
\hline ES (f) & 10 y, $7 \mathrm{mo}$ & Ongoing & 9 drops neat & 23 drops neat & $\begin{array}{l}\text { Lip swelling (ten drops } 10 \% \text { ); lip itched } \\
\text { (eight drops neat) but continued up- } \\
\text { dosing to } 23 \text { drops neat; reduced to } \\
\text { symptom free at nine drops neat. }\end{array}$ \\
\hline $\mathrm{JP}(\mathrm{m})$ & $7 \mathrm{y}, 8 \mathrm{mo}$ & 210 days & $20 \mathrm{~mL}$ neat & $20 \mathrm{~mL}$ neat & $\begin{array}{l}\text { Tingling mouth ( } 20 \text { drops neat); did not } \\
\text { like milk; currently tolerating chocolate } \\
\text { and yogurts, but not in excess. }\end{array}$ \\
\hline MJ (m) & $6 y, 1 \mathrm{mo}$ & 180 days & $100 \mathrm{~mL}$ neat & $100 \mathrm{~mL}$ neat & $\begin{array}{l}\text { Currently tolerating chocolate, cheese, } \\
\text { and milk on cereal. }\end{array}$ \\
\hline TS (m) & $10 y$ & Ongoing & 7 drops neat & 8 drops neat & $\begin{array}{l}\text { Tongue tingling (three drops neat } \\
\text { twice and eight drops neat). }\end{array}$ \\
\hline $\mathrm{Jl}(\mathrm{m})$ & $7 y, 6 \mathrm{mo}$ & 103 days & $40 \mathrm{~mL}$ neat & $40 \mathrm{~mL}$ neat & $\begin{array}{l}\text { Tongue itching (four drops 10\%), } \\
\text { cough, and wheeze (four drops neat). }\end{array}$ \\
\hline OS (m) & $7 y, 1 \mathrm{mo}$ & 92 days & $2 \mathrm{~mL}$ neat & $6 \mathrm{~mL}$ neat & $\begin{array}{l}\text { Cough and dyspnea }(4 \mathrm{~mL}, 5 \mathrm{~mL} \text {, and } \\
6 \mathrm{~mL} \text { neat). }\end{array}$ \\
\hline
\end{tabular}

Abbreviations: CM, cow's milk; CM-SOTI, cow's milk - specific oral tolerance induction; f, female; m, male; mo, months; $y$, years.

at their convenience, not the institution's, especially in the winter months when elective admissions are often deferred because of lack of available hospital beds.

In our clinical program, we have so far in our first 50 patients achieved a success rate of full and partial tolerance of $64 \%$. Our patient group were beyond the age at which natural tolerance is most likely to develop and hence had confirmed persistent milk allergy. ${ }^{3}$ The rates of success previously reported ranged widely, from a similar two-thirds to as high as $100 \% .^{8,12,19}$ Explanations for the differences in outcome may be the sample size (CM-SOTI treatment groups ranged from 4-30 subjects), ${ }^{12,13}$ pretreatment tolerance, ${ }^{15,16}$ individual severity, ${ }^{14}$ and age range, with many series including children under 5 years of age ${ }^{8,10-14,17,19}$ and one series in under 5-year-olds exclusively. ${ }^{20}$ Pretreatment tolerance varied widely from only trace contact triggering symptoms ${ }^{14}$ to the ability to tolerate up to $100 \mathrm{~mL}$ of raw milk. ${ }^{16}$ We included among those who failed to achieve any tolerance subjects who withdrew for personal rather than medical reasons, even though in some instances they were able to ingest significant amounts of milk (up to $100 \mathrm{~mL}$ in one case). This was a higher dropout rate than previously reported. ${ }^{17,19-21}$ Possible explanations are either because families were not subject to the same scrutiny as in clinical trials, the longer protocol is not patient-friendly, or because this is a larger cohort and so more representative of actual population compliance.

Allergic symptoms commonly occur during CM-SOTI up-dosing. Most are mild and respond to antihistamines and dose adjustment, although they may occasionally be serious and require treatment with IM adrenaline. Accordant with the experiences of others, we also noted a high prevalence of side effects or allergic symptoms affecting 41 (82\%) patients. IM adrenaline was used in only two participants; one patient was highly atopic with multiple other food allergies and the other had, as determined by further examination, very severe milk allergy with specific immunoglobulin $\mathrm{E}$ to casein of $>100 \mathrm{kU} / \mathrm{L}$. In response, we withdrew both patients from the program. In previous studies that include data on treatment, IM adrenaline was used in nine instances, three of which were at home. ${ }^{15-18}$ Severe reactions are thus more frequent in hospital rapid up-dosing programs. ${ }^{15}$ However, there is a highly reactive population of patients at risk of anaphylaxis irrespective of the speed of up-dosing. In our study, no clinical parameters, 
Table 3 Characteristics of children who failed CM-SOTI

\begin{tabular}{|c|c|c|c|c|c|}
\hline Patient & Age at start & $\begin{array}{l}\text { Length of } \\
\text { treatment }\end{array}$ & $\begin{array}{l}\text { Maximum dose } \\
\text { achieved }\end{array}$ & $\begin{array}{l}\text { Symptoms evolution during CM-SOTI } \\
\text { (triggering dose) }\end{array}$ & Outcome \\
\hline$H G(f)$ & $6 \mathrm{y}, 3 \mathrm{mo}$ & 380 days & $5 \mathrm{~mL}$ neat & $\begin{array}{l}\text { Itchy eyes (seven drops neat); abdominal discomfort } \\
\text { ( } 5 \mathrm{~mL} \text { neat); symptoms persist despite dose reduction. }\end{array}$ & Withdrew \\
\hline $\mathrm{CH}(\mathrm{m})$ & II y, I mo & 50 days & 5 drops neat & $\begin{array}{l}\text { Eczema flared (three drops I\%); eczema flared (five } \\
\text { drops neat). }\end{array}$ & Withdrew \\
\hline UM (f) & $6 \mathrm{y}, 2 \mathrm{mo}$ & 12 days & 20 drops $1 \%$ & Abdominal pain with first dose; vomited (20 drops I\%). & Stopped \\
\hline ST $(\mathrm{m})$ & $13 \mathrm{y}, \mathrm{I} \mathrm{mo}$ & 220 days & $30 \mathrm{~mL}$ neat & $\begin{array}{l}\text { Eczema flared ( } 13 \text { drops } 1 \% \text { ). Cough and wheeze }(50 \mathrm{~mL} \\
\text { neat); symptom-free at } 30 \mathrm{~mL} \text { neat; missed one dose; } \\
\text { exercise after dose triggered anaphylaxis; given IM } \\
\text { adrenaline. }\end{array}$ & Stopped \\
\hline$M W(f)$ & $5 \mathrm{y}, 6 \mathrm{mo}$ & 60 days & $100 \mathrm{~mL}$ neat & $\begin{array}{l}\text { Abdominal discomfort (ten drops neat and } 30 \mathrm{~mL} \text { neat); } \\
\text { vomited at } 100 \mathrm{~mL} \text { neat; unable to tolerate after dose } \\
\text { reduction. }\end{array}$ & Withdrew \\
\hline $\mathrm{DF}(\mathrm{m})$ & $6 y$ & |4| days & 20 drops neat & $\begin{array}{l}\text { Pruritus ( } 14 \text { drops neat), pruritus and erythema } \\
\text { (20 drops neat) }\end{array}$ & Withdrew \\
\hline$M S(f)$ & $8 \mathrm{y}, 4 \mathrm{mo}$ & - & - & Developed generalized rash while on holiday abroad. & Withdrew \\
\hline SM $(m)$ & 8 y, 9 mo & 120 days & 3 drops $10 \%$ & $\begin{array}{l}\text { Abdominal symptoms during first } 3 \text { weeks; failed to } \\
\text { progress. }\end{array}$ & Stopped \\
\hline TK $(f)$ & $8 \mathrm{y}, 2 \mathrm{mo}$ & 40 days & 20 drops $10 \%$ & Poor compliance; uncertain about clinical reactions. & Stopped \\
\hline $\mathrm{KW}(\mathrm{f})$ & 8 y, 7 mo & 42 days & I drop I\% & $\begin{array}{l}\text { Face and eyes swelled with first dose; unable to contact } \\
\text { family. }\end{array}$ & Stopped \\
\hline $\mathrm{BW}(\mathrm{m})$ & $6 y$ & 30 days & 10 drops $1 \%$ & Rhinitis; persisted despite dose reduction. & Withdrew \\
\hline $\mathrm{DM}(\mathrm{m})$ & 14 y, 9 mo & 120 days & 6 drops neat & Tongue tingling (six drops neat), persists on $10 \%$. & Stopped \\
\hline $\mathrm{NB}(\mathrm{m})$ & 9 y, 5 mo & 40 days & 20 drops $1 \%$ & Abdominal discomfort and diarrhea from first week. & Stopped \\
\hline ZW (m) & 7 y, 8 mo & 50 days & 6 drops neat & Eczema flared (six drops neat); persists at 10 drops $10 \%$. & Stopped \\
\hline $\mathrm{MP}(\mathrm{m})$ & $14 \mathrm{y}, 6 \mathrm{mo}$ & 30 days & 10 drops $10 \%$ & Mouth tingling (nine drops $10 \%$ ), persists on 10 drops $1 \%$. & Stopped \\
\hline $\operatorname{RE}(m)$ & $7 y$ & 200 days & 8 drops neat & $\begin{array}{l}\text { Eczema flared; increased use of salbutamol for asthma; } \\
\text { anaphylactic reaction ( } 8 \text { drops neat); given IM adrenaline. }\end{array}$ & Stopped \\
\hline $\mathrm{OK}(\mathrm{m})$ & $6 y$ & 7 days & 3 drops $1 \%$ & Rhinitis; child unhappy to continue. & Withdrew \\
\hline$H D(f)$ & 7 y, 7 mo & - & 3 drops $10 \%$ & $\begin{array}{l}\text { Eczema flared (two drops I\%), persists with up-dosing; } \\
\text { asthma symptoms (three drops } 10 \% \text { ). }\end{array}$ & Stopped \\
\hline
\end{tabular}

Notes: Dose of CM ingested expressed as 1\%, 10\% or neat. Outcome classified as "withdrew" where child or family unhappy to continue or "stopped" by clincal team. Abbreviations: CM-SOTI, cow's milk - specific oral tolerance induction; f, female; IM, intramuscular; m, male; mo, months; $y$, years.

including previous symptom severity, differentiated between subjects who did or did not achieve full tolerance; the latter had more frequent and severe allergic symptoms. Longo et a ${ }^{14}$ have also demonstrated successful tolerance induction in a group of children selected for treatment because they presented with very severe cow's milk-induced reactions. The severity, therefore, of preceding allergic reactions does not seem to be a useful guide in predicting severe adverse reactions in CMSOTI. Vásquez-Ortiz et $\mathrm{al}^{21}$ identified three pretreatment parameters associated with higher severity of allergic symptoms:

Table 4 Type and prevalence of allergic symptoms by response group

\begin{tabular}{lll}
\hline Symptom & Full $(\mathbf{n = 2 3 )}$ & Partial/failed $(\mathbf{n = 2 6})$ \\
\hline Skin & $4(17)$ & $10(38)$ \\
Oral & $5(22)$ & $8(3 I)$ \\
Nasal & $2(9)$ & $4(15)$ \\
Intestinal & $4(17)$ & $7(27)$ \\
Respiratory & 0 & $5(19)$ \\
Anaphylaxis & 0 & $2(8)$ \\
\hline
\end{tabular}

symptom severity at baseline food challenge, cow's milk specific immunoglobulin $\mathrm{E}>50 \mathrm{kU} / \mathrm{L}$, and cow's milk skin prick test $>9 \mathrm{~mm}$ wheal. Their clinical criterion seems to contrast with our experience, possibly because nearly all (96.3\%) of their study patients were in the severe baseline group. They concluded that CM-SOTI was insufficiently safe in $25 \%$ of children. Further studies need to be conducted to identify these at-risk individuals to alert clinicians to provide closer supervision and support before instituting treatment, and thereby enhance safety, particularly of home up-dosing programs.

SOTI contrasts with AIT, the only other immune modulation treatment modality in routine clinical practice, in two respects. Firstly, SOTI requires continued allergen exposure to maintain its effect, while AIT remains effective up to at least 10 years after completion of the 3-year treatment program..$^{9,24,32}$ The ultimate measure therefore of SOTI success is long-term compliance and whether allergic symptoms, particularly severe symptoms, occur 


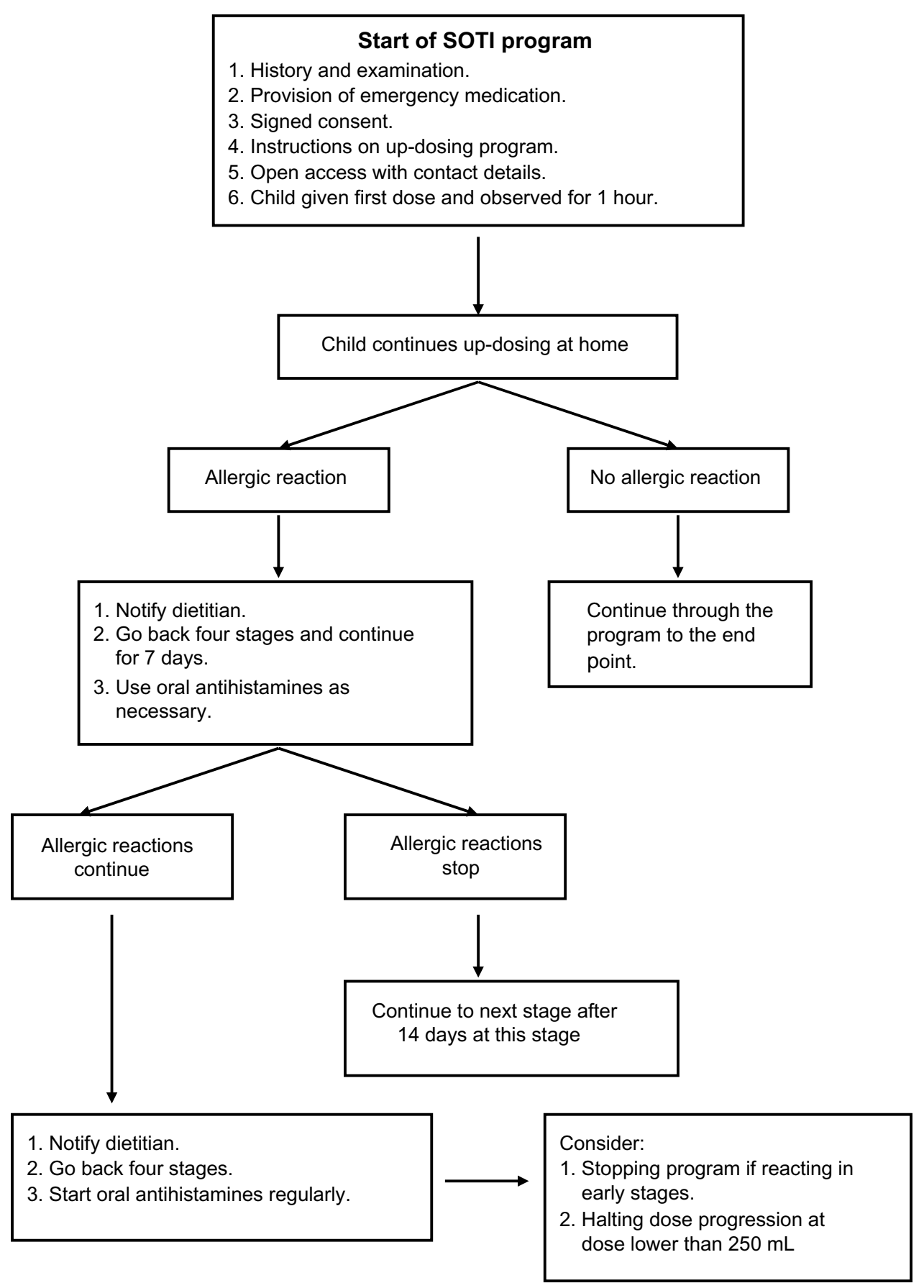

Figure 2 Management of progress during up-dosing.

Abbreviation: SOTI, specific oral tolerance induction.

after prolonged exposure. We continue follow-up with our patients and have done so at the time of writing for a mean of 49 months. All 30 patients still under follow-up continue with regular milk ingestion. Meglio et a ${ }^{25}$ reported similar success at review at 4 years and 8 months. No subject reported use of emergency care. The second difference between SOTI and AIT, particularly pollen AIT, is the clinical end-point. In SOTI, success is measured by total absence of symptoms, while AIT is regarded successful if the treatment effects are significantly better than placebo, even though the patients still experience symptoms..$^{32,33}$ Where pollen counts are low, all AIT treatment patients would be expected to be free from symptoms. This could be considered equivalent to partial tolerance in SOTI, so in this respect, both full and partial tolerance should be regarded treatment success.

In conclusion, we have demonstrated that a CM-SOTI program can be successfully and safely implemented as 
routine clinical practice with acceptable patient compliance during up-dosing, when allergic symptoms are common, and for up to 4 years after initiation of treatment. While there remains a risk to individual patients of severe allergic reactions, we believe that the benefit of CM-SOTI is greater than the continuing risks of persistent allergy. We propose therefore that CM-SOTI, like AIT, could be more widely offered to patients after being made aware of its risks but with the protection of available emergency medication and physician support.

\section{Disclosure}

The authors report no conflicts of interest in this work.

\section{References}

1. Nowak-Wegrzyn A, Sampson HA. Future therapies for food allergy. J Allergy Clin Immunol. 2011;127(3):558-573.

2. Santos A, Dias A, Pinheiro JA. Predictive factors for the persistence of cow's milk allergy. Pediatr Allergy Immunol. 2010;21(8):1127-1134.

3. Fiocchi A, Schünemann HJ, Brozek J, et al. Diagnosis and Rationale for Action Against Cow's Milk Allergy (DRACMA): a summary report. J Allergy Clin Immunol. 2010;126(6):1119-1128.

4. Saarinen KM, Pelkonen AS, Mäkelä MJ, Savilahti E. Clinical course and prognosis of cow's milk allergy are dependent on milk-specific IgE status. J Allergy Clin Immunol. 2005;116(4):869-875.

5. Niggemann B, Staden U, Rolinck-Werninghaus C, Beyer K. Specific oral tolerance induction in food allergy. Allergy. 2006;61(7):808-811.

6. Patriarca G, Schiavino D, Nucera E, Schinco G, Milani A, Gasbarrini GB. Food allergy in children: results of a standardized protocol for oral desensitization. Hepatogastroenterology. 1998;45(19):52-58.

7. Patriarca G, Nucera E, Roncallo C, et al. Oral desensitizing treatment in food allergy: clinical and immunological results. Aliment Pharmacol Ther. 2003;17(3):459-465.

8. Meglio P, Bartone E, Plantamura M, Arabito E, Giampietro PG. A protocol for oral desensitization in children with IgE-mediated cow's milk allergy. Allergy. 2004;59(9):980-987.

9. Staden U, Rolinck-Werninghaus C, Brewe F, Wahn U, Niggemann B, Beyer K. Specific oral tolerance induction in food allergy in children: efficacy and clinical patterns of reaction. Allergy. 2007;62(11): 1261-1269.

10. Patriarca G, Nucera E, Pollastrini E, et al. Oral specific desensitization in food-allergic children. Dig Dis Sci. 2007;52(7):1662-1672.

11. Martorell Aragonés A, Félix Toledo R, Cerdá Mir JC, Martorell Calatayud A. Oral rush desensitization to cow milk. Following of desensitized patients during three years. Allergol Immunopathol (Madr). 2007;35(5):174-176.

12. Morisset M, Moneret-Vautrin DA, Guenard L, et al. Oral desensitization in children with milk and egg allergies obtains recovery in a significant proportion of cases. A randomized study in 60 children with cow's milk allergy and 90 children with egg allergy. Eur Ann Allergy Clin Immunol. 2007;39(1):12-19.

13. Staden U, Blumchen K, Blankenstein N, et al. Rush oral immunotherapy in children with persistent cow's milk allergy. J Allergy Clin Immunol. 2008;122(2):418-419.

14. Longo G, Barbi E, Berti I, et al. Specific oral tolerance induction in children with very severe cow's milk-induced reactions. J Allergy Clin Immunol. 2008;121(2):343-347.

15. Skripak JM, Nash SD, Rowley H, et al. A randomized, double-blind, placebo-controlled study of milk oral immunotherapy for cow's milk allergy. J Allergy Clin Immunol. 2008;122(6):1154-1160.
16. Zapatero L, Alonso E, Fuentes V, Martinez MI. Oral desensitization in children with cow's milk allergy. J Investig Allergol Clin Immunol. 2008;18(5):389-396.

17. Caminiti L, Passalacqua G, Barberi S, et al. A new protocol for specific oral tolerance induction in children with IgE-mediated cow's milk allergy. Allergy Asthma Proc. 2009;30(4):443-448.

18. Pajno GB, Caminiti L, Ruggeri P, et al. Oral immunotherapy for cow's milk allergy with a weekly up-dosing regimen: a randomized singleblind controlled study. Ann Allergy Asthma Immunol. 2010;105(5): 376-381.

19. Martorell A, De la Hoz B, Ibáñez MD, et al. Oral desensitization as a useful treatment in 2-year-old children with cow's milk allergy. Clin Exp Allergy. 2011;41(9):1297-1304.

20. Salmivesi S, Korppi M, Mäkelä MJ, Paassilta M. Milk oral immunotherapy is effective in school-aged children. Acta Paediatr. 2013;102(2):172-176.

21. Vázquez-Ortiz M, Alvaro-Lozano M, Alsina L, et al. Safety and predictors of adverse events during oral immunotherapy for milk allergy: severity of reaction at oral challenge, specific IgE and prick test. Clin Exp Allergy. 2013;43(1):92-102.

22. Sopo SM, Onesimo R, Giorgio V, Fundarò C. Specific oral tolerance induction (SOTI) in pediatric age: clinical research or just routine practice? Pediatr Allergy Immunol. 2010;21(2 Pt 2):e446-e449.

23. Baena-Cagnani CE, Passalacqua G, Baena-Cagnani RC, Croce VH, Canonica WG. Sublingual immunotherapy in pediatric patients: beyond clinical efficacy. Curr Opin Allergy Clin Immunol. 2005;5(2): 173-177.

24. Rolinck-Werninghaus C, Staden U, Mehl A, Hamelmann E, Beyer K, Niggemann B. Specific oral tolerance induction with food in children: transient or persistent effect on food allergy? Allergy. 2005;60(10):1320-1322.

25. Meglio P, Giampietro PG, Gianni S, Galli E. Oral desensitization in children with immunoglobulin E-mediated cow's milk allergy follow-up at 4 yr and 8 months. Pediatr Allergy Immunol. 2008;19(5): 412-419.

26. Nowak-Wegrzyn A, Fiocchi A. Rare, medium, or well done? The effect of heating and food matrix on food protein allergenicity. Curr Opin Allergy Clin Immunol. 2009;9(3):234-237.

27. Kim JS, Nowak-Wegrzyn A, Sicherer SH, Noone S, Moshier EL, Sampson HA. Dietary baked milk accelerates the resolution of cow's milk allergy in children. J Allergy Clin Immunol. 2011;128(1): 125-131.

28. Eigenmann PA, Atanaskovic-Markovic M, O'B Hourihane J, et al; European Academy of Allergy and Clinical Immunology Section on Pediatrics; European Academy of Allergy and Clinical Immunology-Clemens von Pirquet Foundation. Testing children for allergies: why, how, who and when: an updated statement of the European Academy of Allergy and Clinical Immunology (EAACI) Section on Pediatrics and the EAACI-Clemens von Pirquet Foundation. Pediatr Allergy Immunol. 2013;24(2):195-209.

29. SOFA, Statistics Open For All. The user-friendly, pen-source statistics, analysis, and reporting package. Available from: http://www. sofastatistics.com/home.php. Accessed December 10, 2013.

30. Krishna MT, Ewan PW, Diwakar L, et al; British Society for Allergy and Clinical Immunology. Diagnosis and management of hymenoptera venom allergy: British Society for Allergy and Clinical Immunology (BSACI) guidelines. Clin Exp Allergy. 2011;41(9):1201-1220.

31. Birnbaum J, Charpin D, Vervloet D. Rapid Hymenoptera venom immunotherapy: comparative safety of three protocols. Clin Exp Allergy. 1993;23(3):226-230.

32. Eng PA, Reinhold M, Gnehm HP. Long-term efficacy of preseasonal grass pollen immunotherapy in children. Allergy. 2002;57(4):306-312.

33. Durham SR, Emminger W, Kapp A, et al. Long-term clinical efficacy in grass pollen-induced rhinoconjunctivitis after treatment with SQ-standardized grass allergy immunotherapy tablet. J Allergy Clin Immunol. 2010;125(1):131-138. 
Journal of Asthma and Allergy

\section{Publish your work in this journal}

The Journal of Asthma and Allergy is an international, peer-reviewed open-access journal publishing original research, reports, editorials and commentaries on the following topics: Asthma; Pulmonary physiology; Asthma related clinical health; Clinical immunology and the immunological basis of disease; Pharmacological interventions and

new therapies. Issues of patient safety and quality of care will also be considered. The manuscript management system is completely online and includes a very quick and fair peer-review system, which is all easy to use. Visit http://www.dovepress.com/testimonials.php to read real quotes from published authors.

Submit your manuscript here: http://www.dovepress.com/journal-of-asthma-and-allergy-journal 